\title{
Engineering smooth muscle tissue with a predefined structure
}

\author{
Byung-Soo Kim, ${ }^{1}$ David J. Mooney ${ }^{1,2}$ \\ ${ }^{1}$ Department of Chemical Engineering, University of Michigan, Ann Arbor, Michigan 48109-2136 \\ ${ }^{2}$ Department of Biologic and Materials Sciences, University of Michigan, Ann Arbor, Michigan 48109
}

Received 14 May 1997; accepted 10 December 1997

\begin{abstract}
Nonwoven meshes of polyglycolic acid (PGA) fibers are attractive synthetic extracellular matrices (ECMs) for tissue engineering and have been used to engineer many types of tissues. However, these synthetic ECMs lack structural stability and often cannot maintain their original structure during tissue development. This makes it difficult to design an engineered tissue with a predefined configuration and dimensions. In this study, we investigated the ability of PGA fiber-based matrices bonded at their fiber crosspoints with a secondary polymer, poly-L-lactic acid (PLLA), to resist cellular contractile forces and maintain their predefined structure during the process of smooth muscle (SM) tissue development in vitro. Physically bonded PGA matrices exhibited a 10- to 35-fold increase in the compressive modulus over unbonded PGA matrices, depending on the mass of PLLA utilized to bond the PGA matrices. In addition, the bonded PGA matrices degraded much more slowly than the unbonded matrices. The PLLA bonding of PGA matrices had no effect on the ability of cells to adhere to the matrices. After 7 weeks in culture, the bonded matrices maintained
\end{abstract}

$101 \pm 4 \%$ of their initial volume and an approximate original shape while the unbonded matrices contracted to $5 \pm 1 \%$ of their initial volume with an extreme change in their shape. At this time the bonded PGA matrices had a high cellularity, with smooth muscle cells (SMCs) and ECM proteins produced by these cells (e.g., elastin) filling the pores between PGA fibers. This study demonstrated that physically bonded PGA fiber-based matrices allow the maintenance of the configuration and dimensions of the original matrices and the development of a new tissue in a predefined threedimensional structure. This approach may be useful for engineering a variety of tissues of various structures and shapes, and our study demonstrates the importance of matching both the initial mechanical properties and the degradation rate of a matrix to the specific tissue one is engineering. (C) 1998 John Wiley \& Sons, Inc. J Biomed Mater Res, 41, 322-332, 1998.

Key words: tissue engineering; synthetic extracellular matrix; polyglycolic acid; poly-L-lactic acid; smooth muscle

\section{INTRODUCTION}

The roles of exogenous ECMs in tissue engineering include providing mechanical support and defining a potential space for tissue development. Exogenous ECMs used for tissue engineering should serve as templates, guiding cells to regenerate new tissues with predefined shapes and sizes. ${ }^{1}$ It also is desirable for exogenous ECMs to resorb after accomplishment of new tissue formation. Both synthetic and natural materials have been served as exogenous ECMs. These biomaterials include $\mathrm{PGA}^{2-4}$ polylactic acid (PLA), ${ }^{3,5}$ polylactic-co-glycolic acid (PLGA), ${ }^{3,5-7}$ calcium phosphate ceramics, ${ }^{8}$ collagen, ${ }^{9,10}$ alginate, ${ }^{11}$ hyaluro-

Correspondence to: D. Mooney; e-mail: mooneyd@engin. umich.edu

Contract grant sponsor: National Science Foundation; Contract grant number: BES-9501376

(C) 1998 John Wiley \& Sons, Inc. CCC 0021-9304/98/020322-11 nate, ${ }^{12,13}$ and laminin. ${ }^{14}$ Synthetic polymer matrices can be fabricated reproducibly, and their mechanical properties and degradation rates readily can be controlled and manipulated. In contrast, naturally derived materials can suffer from batch-to-batch variations and exhibit a limited range of mechanical properties and degradation rates. ${ }^{1}$

Many types of exogenous ECMs lack the structural stability to withstand forces and cannot support the formation of a new tissue with a predefined structure. Typical forces exerted on the matrices include contractile forces from cells growing on the matrices, compressive forces from surrounding tissues following implantation, or hydrodynamic fluid flow-induced shear forces when maintained in a bioreactor. PGA fiber-based matrices have proven to be useful in engineering many types of tissues. ${ }^{2-4,15-17}$ These matrices have a high porosity and surface/volume ratio to guarantee cell-polymer interactions, tissue regeneration, and nutritional diffusion. In previous studies, we have engineered SM and dental pulp tissue compa- 
rable to the native tissues in terms of cellularity and/ or ECM protein content using isolated cells and nonwoven meshes PGA fibers. ${ }^{16,17}$ However, these matrices did not withstand the contractile forces exerted by the adherent cells, and this resulted in an extreme contraction of the matrices over time and a loss of the desired size and shape of the engineered tissues. Naturally derived materials also suffer from contraction of exogenous ECMs during tissue development. For example, SM tissues engineered utilizing collagen gels contract significantly over time. ${ }^{9,10}$

A potential approach to engineering tissues with predefined, three-dimensional structures is to utilize highly stable matrices. PGA fiber-based matrices previously have been stabilized with physical bonds of a secondary polymer, PLLA, between adjacent PGA fibers. $^{2}$ In this study, we investigated whether stabilized PGA fiber-based matrices could resist cellular contractile forces and maintain their predefined shape and size during the process of tissue development. The mechanical and degradative properties of stabilized PGA fiber-based matrices were examined to investigate the structural stability of the matrices. These matrices then were utilized to engineer SM tissue in vitro to determine if SM tissue with a predefined structure could be formed from the matrices.

\section{MATERIALS AND METHODS}

\section{Fabrication of stabilized PGA matrices}

PGA fiber-based matrices (fibers approximately $12 \mu \mathrm{m}$ in diameter) assembled into nonwoven arrays were purchased from Albany Int. (Taunton, MA). The porosity of the PGA matrix was approximately $97 \%$. The crystallinity of PGA fiber was $57 \%$, as measured by differential scanning calorimetry. The inherent viscosity of PGA was $1.23 \mathrm{dL} / \mathrm{g}$, and the residual monomer content was less than $0.3 \%$. PGA matrices $3 \mathrm{~mm}$ in thickness ( $24 \mathrm{mg} / \mathrm{mL}$ bulk density) were used for matrix characterization, and those $0.5 \mathrm{~mm}$ in thickness (100 mg/mL bulk density) were used for SMC seeding and culture. To stabilize matrices, a solution of PLLA (Medisorb, Cincinnati, $\mathrm{OH})$ dissolved in chloroform $(5 \% \mathrm{w} / \mathrm{v})$ was placed in an atomizer (Devilbus Corp.) and sprayed over both sides of a PGA matrix from a distance of 3 in. using a nitrogen stream (18 psi) to atomize the PLLA solution. ${ }^{2}$ The solvent subsequently was allowed to evaporate, and matrices were lyophilized to remove residual solvent. Certain PLLA-bonded matrices were annealed by heating in an oven (Model 5831, Precision Scientific, Inc., Chicago, IL) at $195^{\circ} \mathrm{C}$ under vacuum for $30 \mathrm{~min}$ and subsequently cooling to room temperature. Differential scanning calorimetry of bonded and annealed PGA matrices indicated an increased PLLA crystallinity after the annealing process (not shown).

\section{Characterization of stabilized PGA matrices}

The mass of PLLA bonded to PGA matrices was determined by weighing PGA devices before and after spraying.
For scanning electron microscopic examination, samples were coated with gold using a sputter coater (Desk II, Denton Vacuum, Cherry Hill, NJ), and a Hitachi (model S-800) scanning electron microscope was operated at a $5 \mathrm{kV}$ voltage to image samples. The compressional properties of unbonded PGA matrices $(n=3)$, bonded, and bonded and annealed PGA matrices were tested using a mechanical tester (model 810, MTS Systems Corp., Eden Prairie, MN) initially after fabrication and following incubation in PBS at $37^{\circ} \mathrm{C}$ over a 5-week period. Cylindrical samples $12 \mathrm{~mm}$ in diameter and $3 \mathrm{~mm}$ in height were used for a compressional test. A 10-Newton maximum load cell was used, and the cross-head speed was $1 \mathrm{~mm} / \mathrm{min}$. Before the compressional testing, samples were pre-wet by placing the samples for 24 $h$ in a vial containing water. The compressive modulus was obtained from the slope of the initial linear section of the stress-strain curve. The degradation kinetics of unbonded, bonded, and bonded and annealed matrices were determined by measuring the mass loss of the matrices $(n=3)$ incubated in phosphate-buffered saline (PBS, $\mathrm{pH}$ 7.4) under static conditions at $37^{\circ} \mathrm{C}$.

\section{Cell isolation and culture}

SMCs were isolated and cultured using a modification of the techniques described by Rothman et al. ${ }^{18}$ In brief, the cells were isolated from aortas of $300-350 \mathrm{~g}$ adult male Lewis rats (Charles River Laboratories, Wilmington, MA) using an enzymatic dissociation. After fat, adventitia, and connective tissue surrounding the arteries were removed by blunt dissection, the SM tissue was cut into multiple small pieces and placed into a spinner flask containing an enzymatic dissociation buffer at $37^{\circ} \mathrm{C}$. This buffer contained 0.125 $\mathrm{mg} / \mathrm{mL}$ elastase (Sigma Chemical Co., St. Louis, MO), 1.0 $\mathrm{mg} / \mathrm{mL}$ collagenase (CLS type I, 204 units / mg, Worthington Biochemical Corp., Freehold, NJ), $0.250 \mathrm{mg} / \mathrm{mL}$ soybean trypsin inhibitor (type 1-S, Sigma), and $2.0 \mathrm{mg} / \mathrm{mL}$ crystallized bovine serum albumin (Gibco/Life Technologies, Gaithersburg, MD). After $90 \mathrm{~min}$ of incubation, the suspension was filtered through a $100 \mu \mathrm{m}$ Nitex filter (Tetko, Inc., Briarcliff Manor, NY) and centrifuged at $200 \mathrm{~g}$ for $5 \mathrm{~min}$. The pellet was resuspended in Medium 199 (Sigma) supplemented with $20 \%$ (v/v) fetal bovine serum (FBS, Gibco), 2 $\mathrm{mM}$ of L-glutamine (Gibco), and 50 units / $\mathrm{mL}$ of penicillinstreptomycin (Gibco). The cells were cultured on tissue culture plastic in a humidified $5 \% \mathrm{CO}_{2}$ atmosphere with the medium [Medium 199, 10\% (v/v) fetal bovine serum, 50 units/mL penicillin-streptomycin] changed every other day. Cells from passage 7 were used in the experiments in this study.

\section{Cell seeding and subsequent culture}

PGA matrices bonded with PLLA (the mass of PLLA $=51$ or $136 \%$ of the initial PGA mass) were used as stabilized PGA matrices in the study of SM tissue development. Unbonded PGA matrices were used as a control. Prior to cell 
seeding, matrices were cut into squares $(5 \times 5 \mathrm{~mm})$ and pre-wet in Medium 199 containing 10\%(v/v) FBS for $24 \mathrm{~h}$. Matrices were seeded with an agitated seeding method previously described. ${ }^{16}$ A very high cell seeding density can be obtained from this seeding method. In brief, SMCs $(0.5 \mathrm{~mL} \times$ $2 \times 10^{7}$ cells $/ \mathrm{mL}$ ) and a single matrix were placed in a $50 \mathrm{~mL}$ tube in a humidified $5 \% \mathrm{CO}_{2}$ atmosphere and agitated using an orbital shaker (Bellco Glass, Inc., Vineland, NJ) at $100 \mathrm{rpm}$ for $24 \mathrm{~h}$. Seeded matrices subsequently were washed in phosphate-buffered saline (PBS), placed in a spinner flask (Bellco Glass, Inc.), and cultured at $40 \mathrm{rpm}$ in a humidified 5\% $\mathrm{CO}_{2}$ atmosphere with the medium changed every other day.

\section{Tissue characterization}

For scanning electron microscopic examination, samples were fixed in $1 \%$ glutaraldehyde and $0.1 \%$ formaldehyde for $30 \mathrm{~min}$ and $24 \mathrm{~h}$, respectively, dehydrated in a graded series of ethanol/water solutions, dried, and then sputter coated with gold. A scanning electron microscope (ISI-DS 130, Topcon Technologies, Pleasanton, CA) was operated at a $10 \mathrm{kV}$ voltage to image samples. The volume of cell-polymer constructs was determined by measuring the dimensions of cell-polymer constructs macroscopically and microscopically. The number of cells in the matrices was determined by measuring the amount of DNA in enzyme-digested triplicate samples using Hoechst 33258 dye and a fluorometer (Hoefer DyNA Quant 200, Pharmacia Biotech, Uppsala, Sweden). ${ }^{19}$ For this assay, samples were washed with PBS three times, lyophilized, and digested in proteinase $\mathrm{K}(0.5$ $\mathrm{mg} / \mathrm{mL}$ proteinase $\mathrm{K}$ and $0.1 \mathrm{mg} / \mathrm{mL}$ SDS in a buffer solution of $50 \mathrm{mM}$ Tris- $\mathrm{HCl}, 0.1 \mathrm{M}$ EDTA, $0.2 \mathrm{M} \mathrm{NaCl}, \mathrm{pH} 7.4$ ) for $10 \mathrm{~h}$ at $55^{\circ} \mathrm{C}$ with occasional gentle shaking. For measurement, $5-50 \mu \mathrm{L}$ of a sample was aliquoted into a cuvette and mixed with $2 \mathrm{~mL}$ of dye solution (10 $\mathrm{mM}$ Tris, $1 \mathrm{mM}$ EDTA $\mathrm{Na}_{2} \cdot 2 \mathrm{H}_{2} \mathrm{O}, 0.2 \mathrm{M} \mathrm{NaCl}, 0.1 \mu \mathrm{g} / \mathrm{mL}$ Hoechst 33258 dye). DNA content was calibrated with calf thymus DNA (Pharmacia Biotech) prior to measurement and read using the fluorometer, which has an excitation wave length of $365 \mathrm{~nm}$ and emission of $460 \mathrm{~nm}$. A smooth muscle cell contained 7.6 pg of DNA, as measured with this method. For histological analysis, samples were fixed in $10 \%$ buffered formalin, paraffin embedded, cross sectioned ( $5 \mu \mathrm{m}$ thick), and stained with hematoxylin and eosin (H\&E) and Verhoeff's staining to visualize cells and elastin, respectively. A commercially available assay kit (Fastin elastin assay kit, Accurate Chemical \& Scientific Corp., Westbury, NY) was used to quantitate elastin. Insoluble elastin in cell-polymer constructs was solubilized by hot oxalic acid treatment, precipitated, and mixed with the Fastin dye reagent. The elastin-dye complex then was collected by centrifugation. The dye bound to the elastin pellet was solubilized with the destain reagent. The recovered dye concentration was measured at $513 \mathrm{~nm}$. All quantitative results were obtained from triplicate samples.

\section{RESULTS}

\section{Stabilization of PGA fiber-based matrices with physical bonds of PLLA}

To physically bond adjacent fibers in nonwoven PGA fiber-based matrices, PLLA dissolved in chloro- form $(5 \% \mathrm{w} / \mathrm{v})$ was sprayed over the PGA matrices. PLLA coated the PGA fibers and formed physical bonds between adjacent PGA fibers following solvent evaporation (Fig. 1). Spraying for longer periods increased both the amount of PLLA coated on PGA matrices and the extent of bonding at the crosspoints of PGA fibers. To vary the pattern of bonding between PGA fibers, bonded PGA matrices were annealed at $195^{\circ} \mathrm{C}$ under vacuum for $30 \mathrm{~min}$. PLLA sprayed on PGA fibers melted and condensed largely at the crosspoints of PGA fibers. Extensive fiber bonding was observed after cooling to room temperature (Fig. 2).

Mechanical tests were performed on bonded and bonded and annealed PGA matrices to determine whether physical bonds between PGA fibers enhanced the resistance of PGA matrices to compressive forces. The compressive modulus of bonded and bonded and annealed PGA matrices linearly increased with the mass of PLLA utilized to bond the PGA matrices in a similar pattern (Fig. 3). The compressive modulus of unbonded PGA matrices was $6.7 \pm 0.5$ $\mathrm{kPa}$. The modulus of the matrices bonded with PLLA increased 10- to 35-fold over unbonded PGA matrices in both cases, depending on the mass of bonding PLLA. The compressive modulus of all these matrices decreased over time during incubation in the $\mathrm{pH}$ balanced, isotonic saline solution (Fig. 4). For example, the compressive modulus of unbonded PGA matrices and bonded and annealed PGA matrices decreased to $1.1 \pm 0.0 \mathrm{kPa}$ and $7.2 \pm 3.0 \mathrm{kPa}$, respectively, over a 5 -week period. However, the compressive modulus of bonded PGA matrices was maintained above $25.2 \pm$ $9.7 \mathrm{kPa}$ over the same period. The degradative properties of unbonded, bonded, and bonded and annealed matrices were compared by measuring the mass loss of matrices immersed in the pH-balanced, isotonic saline solution. Unbonded PGA matrices lost approximately $90 \%$ of their mass after 7 weeks whereas bonded PGA matrices lost only $20 \%$ of their mass after 7 weeks (Fig. 5). Bonded and annealed matrices degraded faster than bonded matrices although the degradation rate was slower than that of unbonded matrices.

\section{SM tissue development in vitro on bonded and unbonded PGA matrices}

Bonded (the mass of bonding PLLA $=51$ or $136 \%$ of the initial PGA mass) and bonded and annealed PGA matrices (the mass of bonding PLLA $=51 \%$ of the initial PGA mass) were seeded with SMCs to investigate whether these matrices could be used as suitable matrices for engineering SM tissue. Unbonded PGA matrices were used as a control. Scanning electron microscopic examination of samples $24 \mathrm{~h}$ after cell seed- 


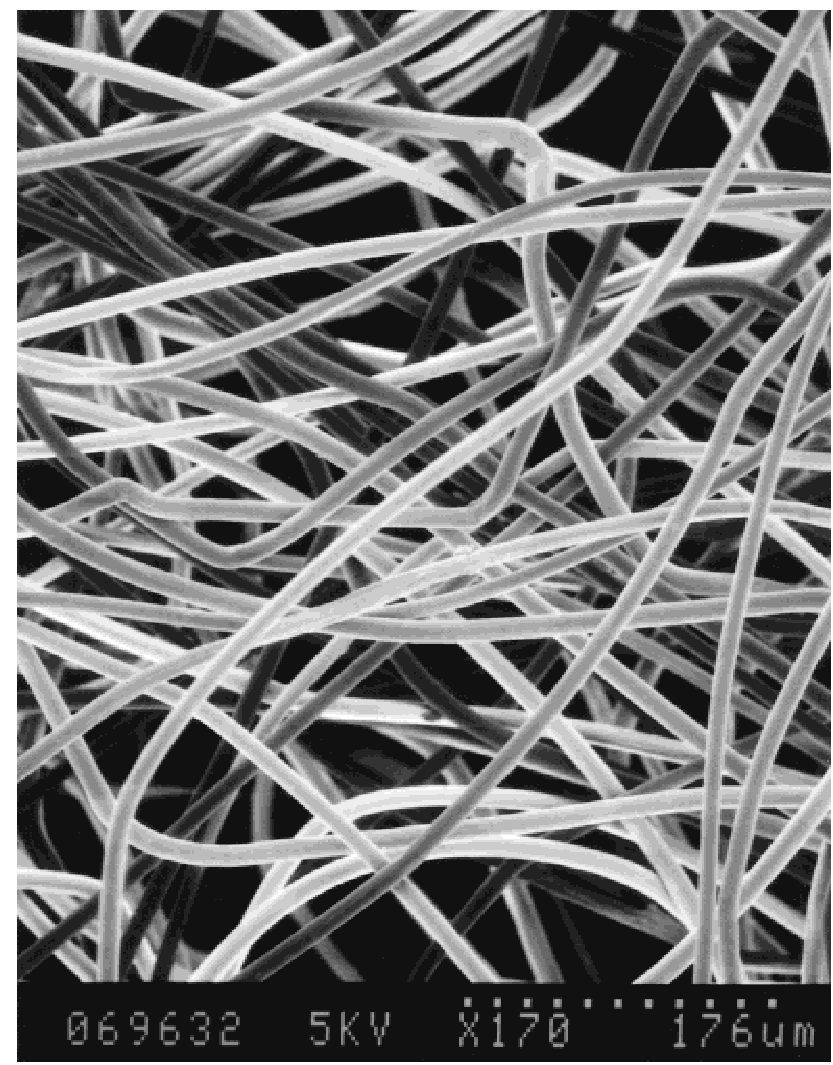

(a)

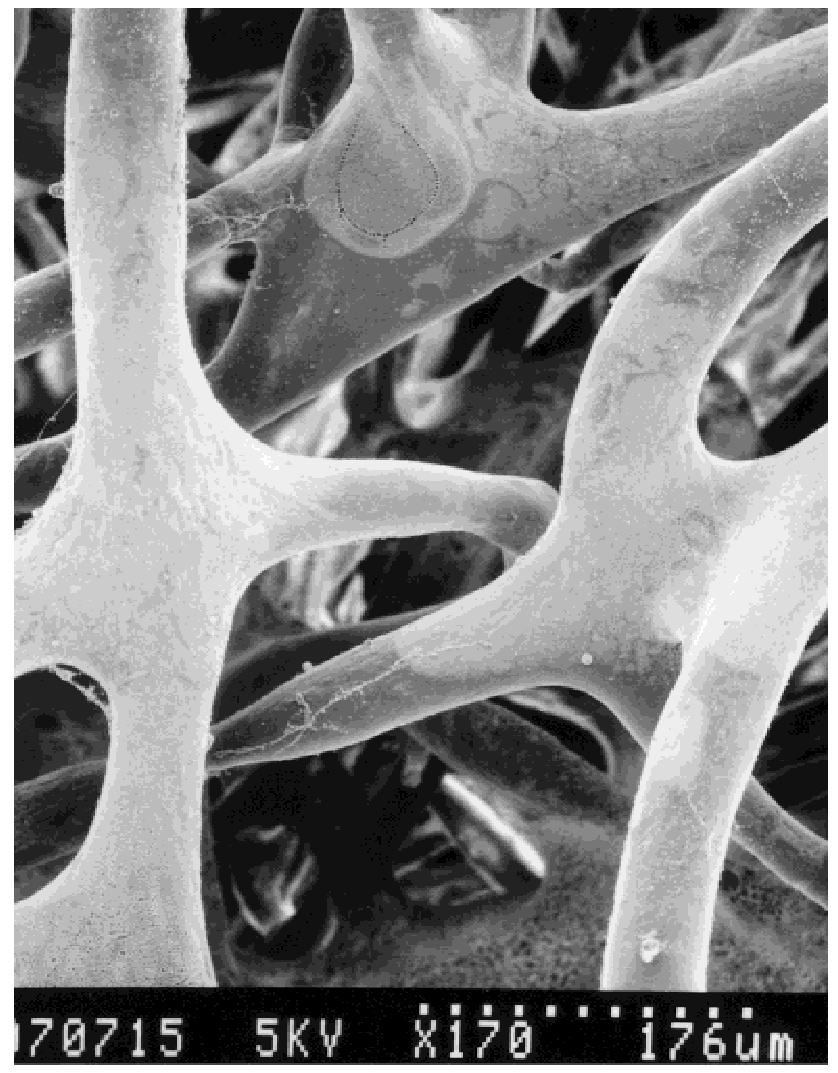

(c)

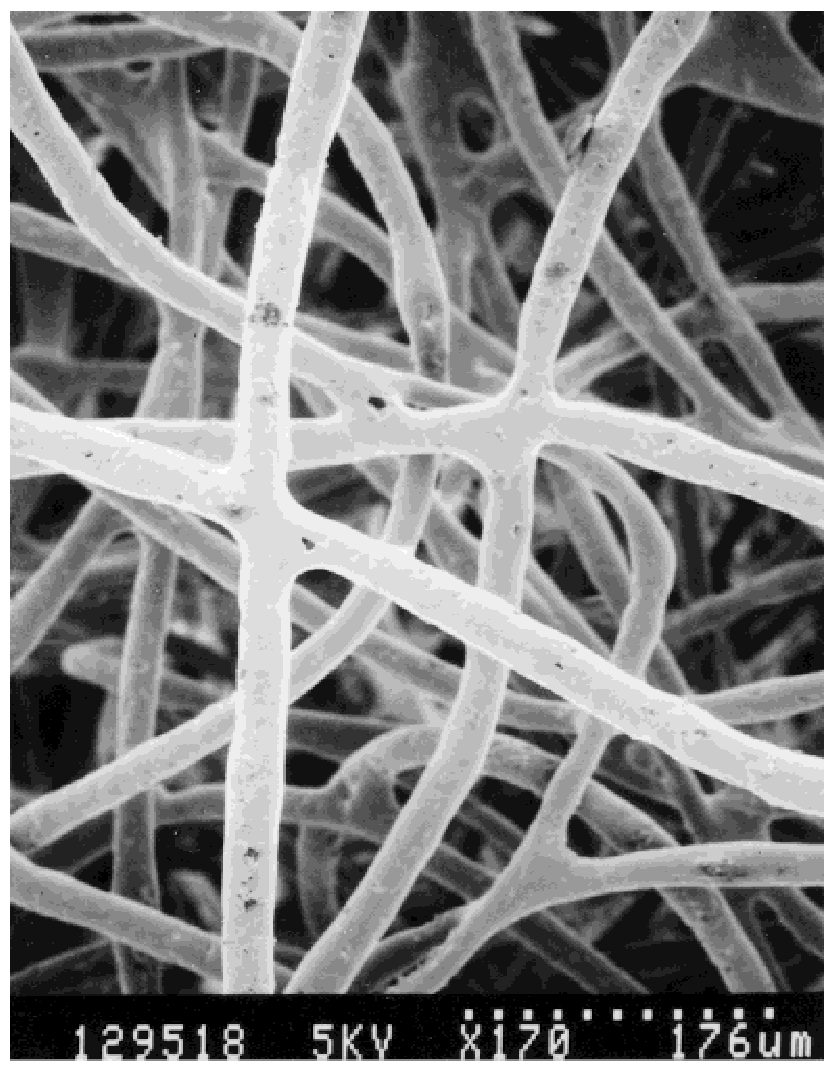

(b)

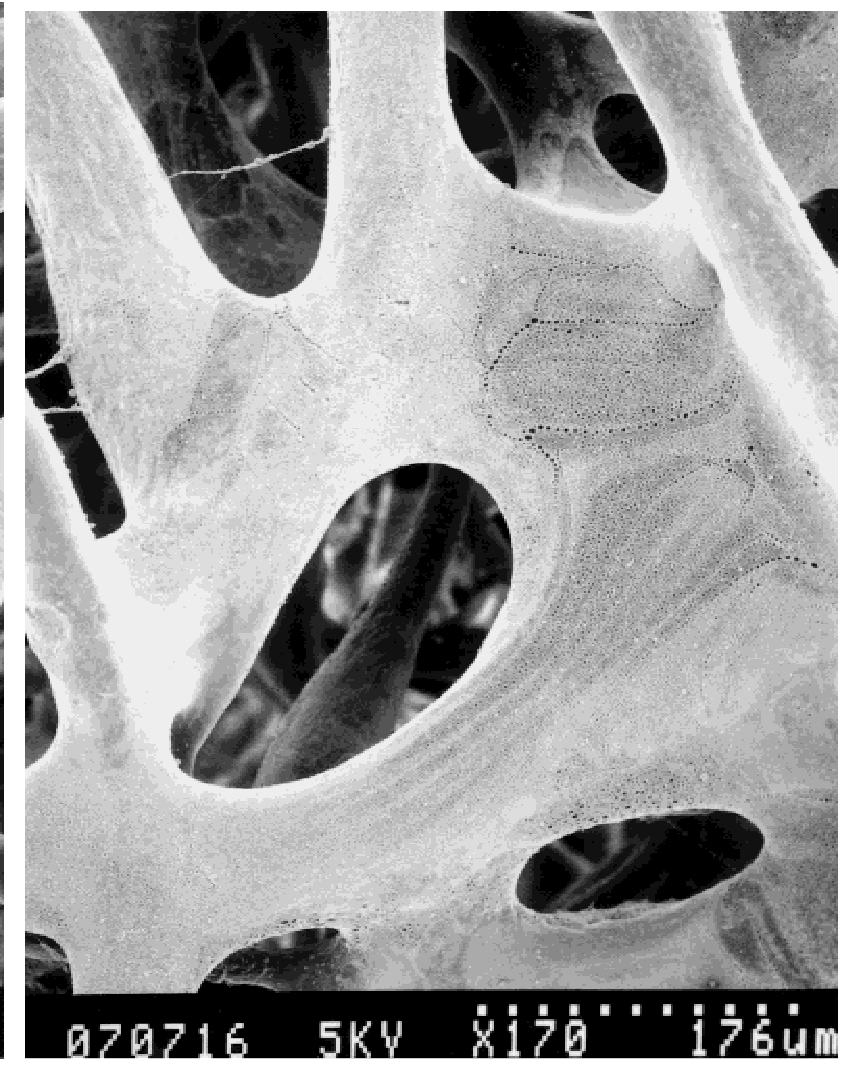

(d)

Figure 1. Scanning electron micrographs of PGA matrices $(1 \times 2 \mathrm{~cm}, 3 \mathrm{~mm}$ thick) sprayed with a solution containing $5 \%$ (w/v) PLLA for (a) 0, (b) 20, (c) 60, and (d) 90 s. The final mass of PLLA bonded to PGA was (a) 0, (b) 69, (c) 265, and (d) 395\% of the initial PGA mass. The original magnifications and size bars are shown in the photomicrographs. 


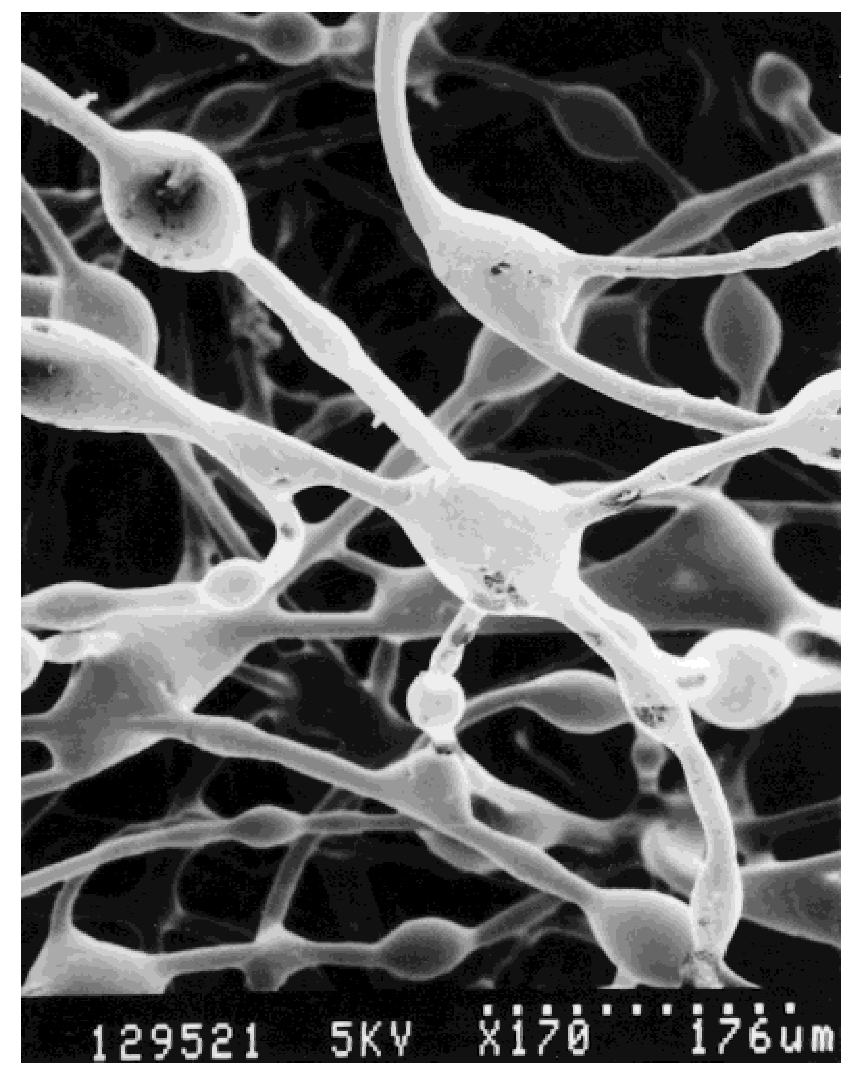

Figure 2. Scanning electron micrograph of the exterior of PLLA-bonded and -annealed PGA matrix. The PGA matrix was sprayed with a solution containing $5 \%(\mathrm{w} / \mathrm{v})$ PLLA (the final mass of bonding PLLA was $65 \%$ of the initial PGA mass) and annealed at $195^{\circ} \mathrm{C}$ under vacuum for $30 \mathrm{~min}$. The original magnification and size bar are shown in the photomicrographs.

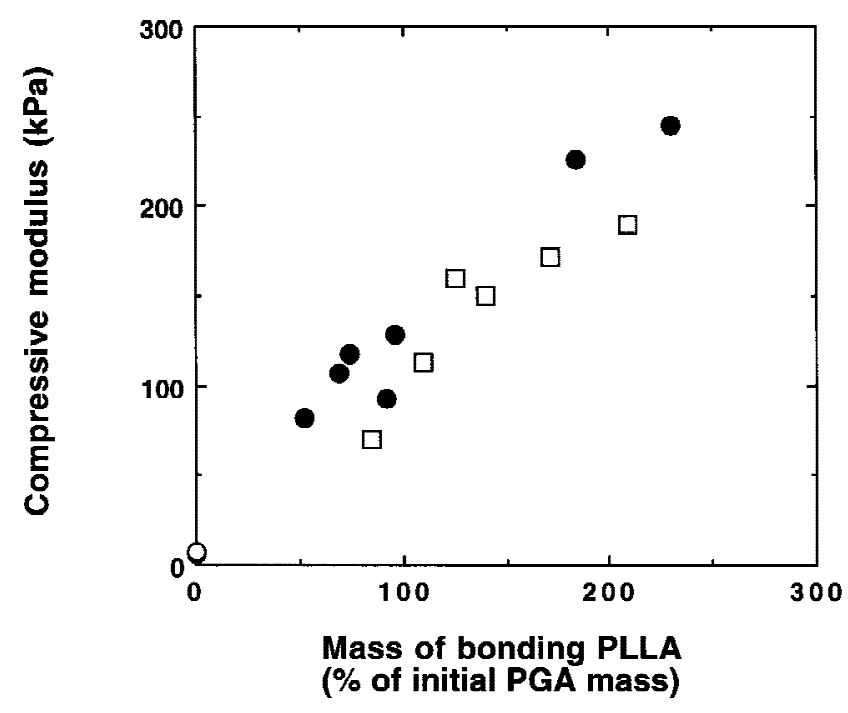

Figure 3. Compressive moduli of unbonded PGA matrices $(\mathrm{O})$, bonded PGA matrices ( $)$, and bonded and annealed PGA matrices (ם) with various amounts of bonding PLLA. Compressive moduli were obtained from the slopes of the initial linear section of stress-strain curves.

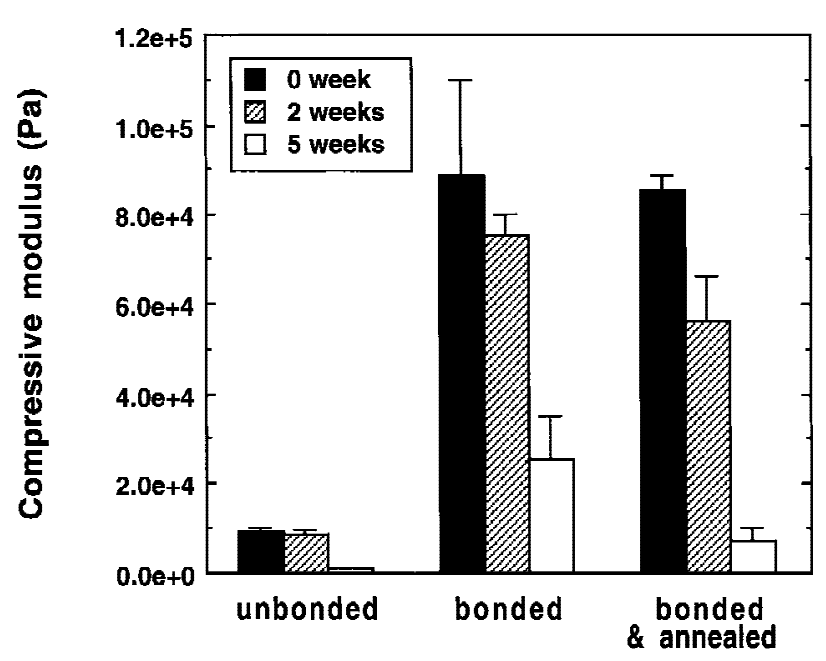

Figure 4. The change in compressive moduli of unbonded, bonded (bonding PLLA mass $=55 \%$ of the initial PGA mass), and bonded and annealed (bonding PLLA mass = $56 \%$ of the initial PGA mass) PGA matrices incubated in PBS at $37^{\circ} \mathrm{C}$ over time.

ing indicated that many cells were adherent and spread along and between fibers of unbonded and bonded matrices (Fig. 6). Rounded cells were visible on top of a layer of well spread cells adherent to polymer fibers [Fig. 6(c)]. However, fewer cells adhered to bonded and annealed PGA matrices. The number of adherent cells $24 \mathrm{~h}$ after cell seeding was quantitated using a fluorometric DNA assay. No statistically sig-

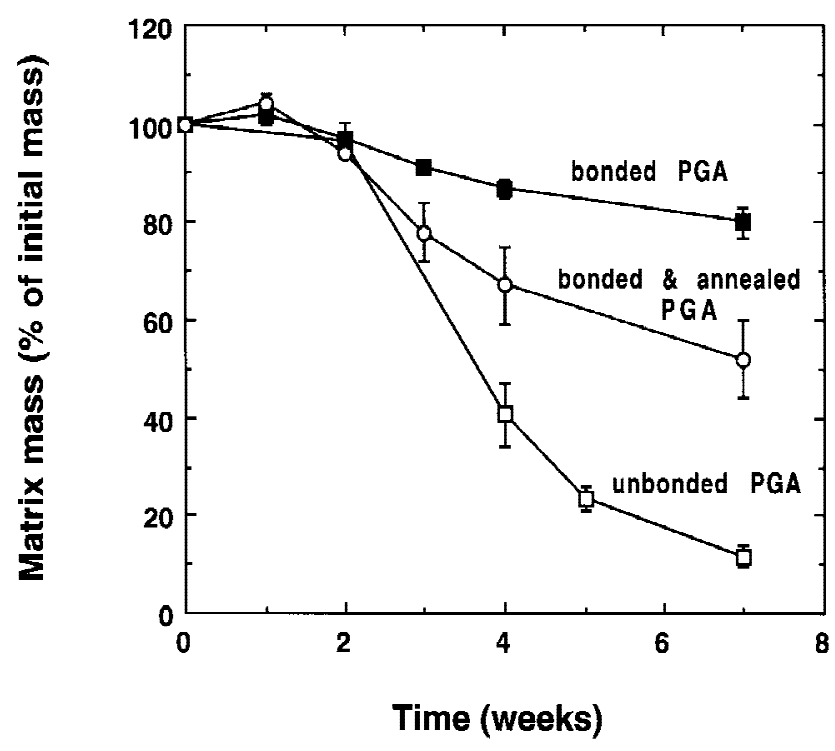

Figure 5. The change in mass over time of PGA matrices, PLLA-bonded PGA matrices, and PLLA-bonded and -annealed PGA matrices. The PLLA-bonded matrices and PLLA-bonded and -annealed PGA matrices contained a mass of PLLA equal to $175 \%$ of the initial PGA mass. Matrices were incubated at $37^{\circ} \mathrm{C}$ under static conditions in PBS during the degradation study. Values represent the mean and standard deviation. 


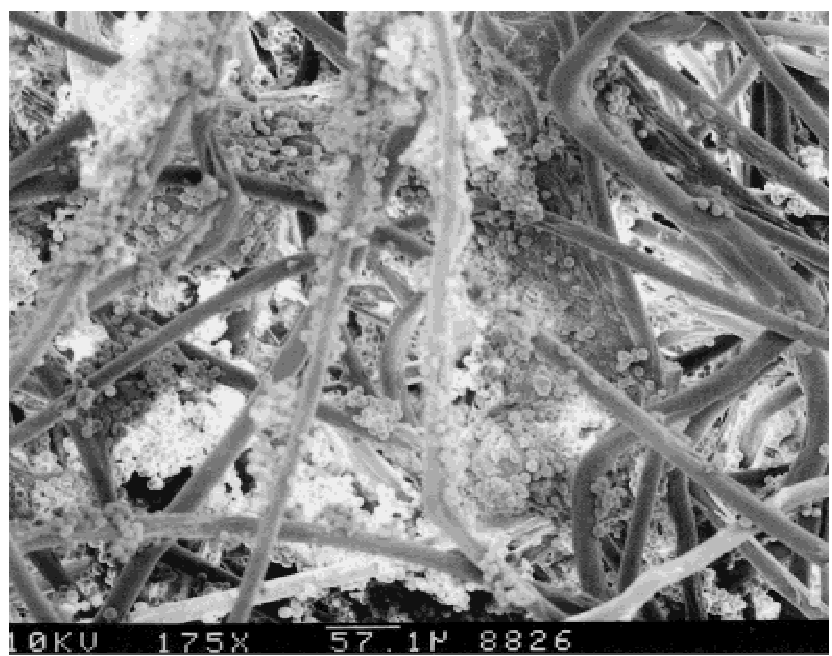

(a)

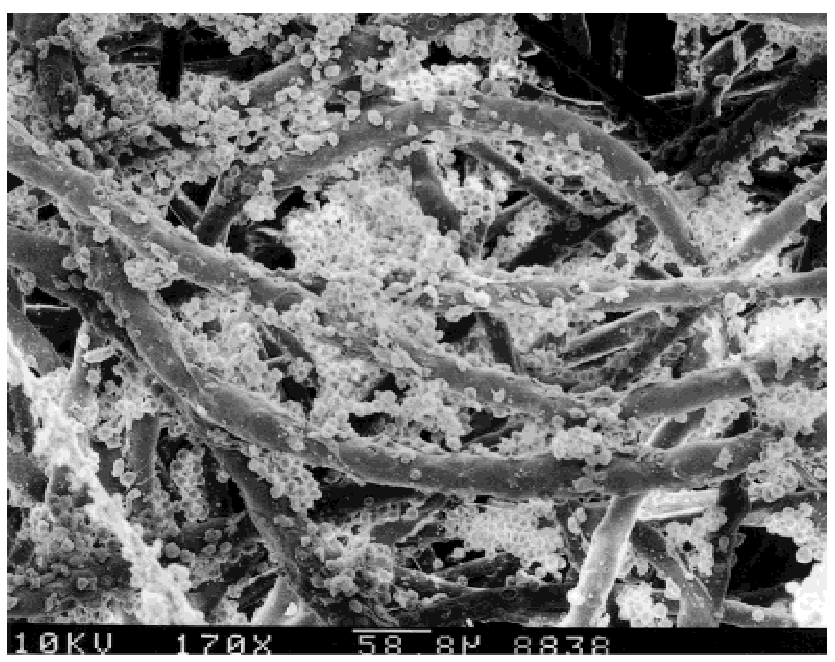

(b)

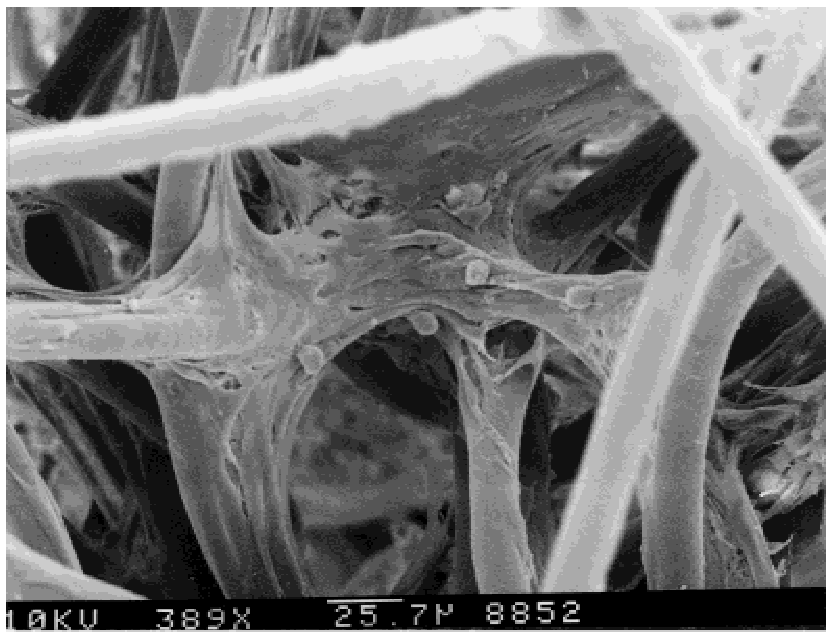

(c)

Figure 6. Scanning electron micrographs of SMCs adherent to (a) unbonded PGA matrix and (b) PLLA-bonded PGA matrix (the mass of bonding PLLA $=51 \%$ of the initial PGA mass) after $24 \mathrm{~h}$ of cell seeding. A closer view of cells on PGA fibers is seen in (c). The original magnifications and size bars are shown in the photomicrographs.

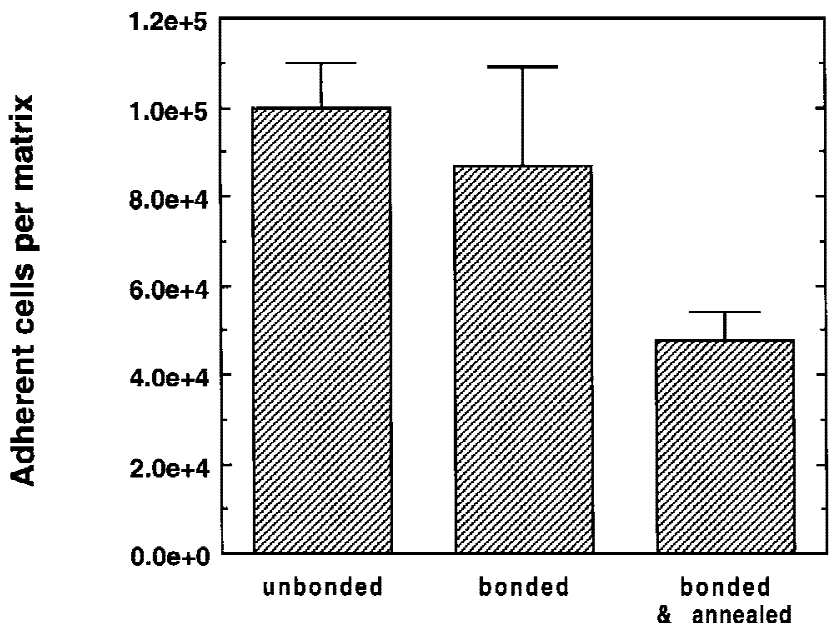

Figure 7. Number of cells adherent to matrices after $24 \mathrm{~h}$ of cell seeding. The number of cells per matrix was determined by a fluorometric DNA assay. Values represent the mean and standard deviation. The difference between the numbers of cells adherent to unbonded PGA matrices and PLLAbonded PGA matrices was not statistically significant while the difference between the numbers of cells adherent to unbonded PGA matrices and PLLA-bonded and -annealed PGA matrices was statistically significant $(p<0.05)$.

nificant difference in the number of cells adherent to unbonded matrices and bonded matrices was noted (Fig. 7). This result indicates that PLLA bonding does not affect the ability of cells to adhere to matrices. However, significantly fewer cells were adhered to bonded and annealed PGA matrices compared to unbonded PGA matrices $(p<0.05)$.

The SMC-seeded matrices described above subsequently were cultured in spinner flasks for up to 7 weeks to determine if stabilized matrices would maintain their original size and shape during tissue development in vitro. Unbonded matrices exhibited extreme contraction after 3 weeks in culture (Fig. 8). For example, the tissue constructs engineered from unbonded matrices dramatically contracted to $5 \pm 1 \%$ of their initial volume over a 7 -week culture period. This likely was caused by the contractile forces exerted by SMCs growing on the matrices. However, bonded matrices resisted the cellular contraction forces and maintained approximately their original size after 7 weeks in culture. The extent of the tissue volume maintenance depended on the mass of bonding PLLA. The matrices bonded with a PLLA mass of 51 and $136 \%$ of the initial PGA mass maintained $70 \pm 6 \%$ and $101 \pm 4 \%$ of their initial volume, respectively, after 7 weeks in culture. In addition, complex tissue shapes could be engineered when bonded matrices were used whereas the predefined shapes of unbonded matrices were lost as the tissues developed (Fig. 9). Bonded and annealed PGA matrices did not maintain their structure (not shown) and fell apart after 4 weeks in culture. Because of the decreased cell adhesion efficiency and structural 


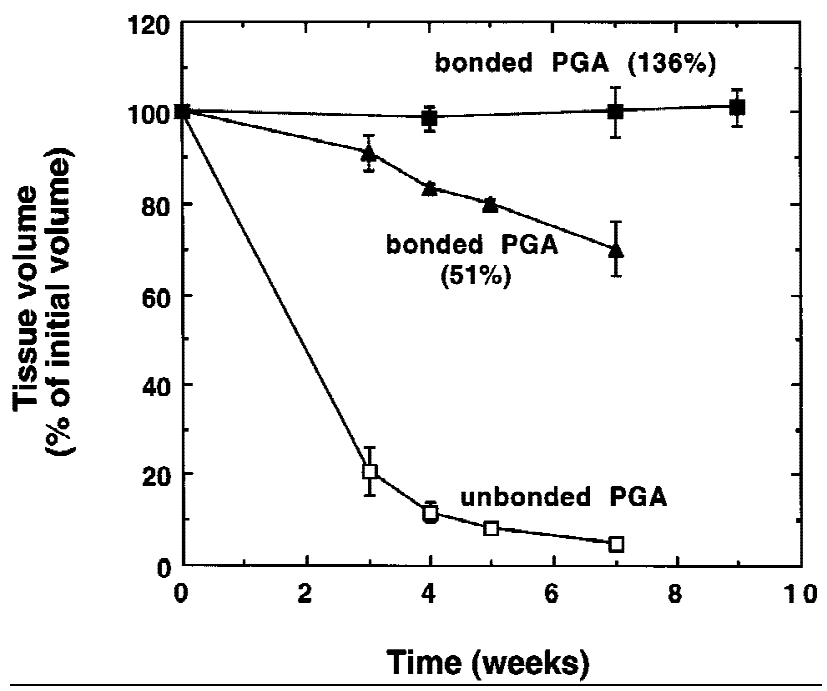

Figure 8. The change in volume of tissue constructs engineered on unbonded PGA matrices and bonded PGA matrices (bonding PLLA mass $=51$ or $136 \%$ of the initial PGA mass) in vitro over time. Values represent the mean and standard deviation.

maintenance failure of bonded and annealed PGA matrices, these matrices were excluded in the remaining experiments.

Scanning electron microscopic graphs [Fig. 10(a,b)] indicated that SMCs adherent to both kinds of matrices proliferated, produced ECM proteins, and filled a large portion of interpolymer-fiber space in a similar pattern after 1 week. After 4 weeks in culture, most of the interpolymer-fiber space on the exterior of the matrices was filled with SMCs and ECM proteins [Fig. $10(c, d)]$. Examination of H\&E-stained cross sections of tissue constructs revealed SMC proliferation and ECM protein deposition throughout the cell-polymer constructs (Fig. 11).

The number of cells in tissue constructs was quantitated by measuring the DNA content of tissue constructs [Fig. 12(a)]. The number of cells growing on unbonded PGA matrices increased until 4 weeks in culture and decreased after that, possibly due to space limitations following matrix contraction. However, the number of cells growing on bonded PGA matrices continued to increase for the 7 weeks of the experiment. The maximum expansion of cells on unbonded PGA matrices and on bonded PGA matrices averaged 16-fold and 23-fold, respectively. The cell density also was calculated as a function of culture time [Fig. 12(b)]. The density of cells on unbonded PGA matrices increased to $9.8 \pm 2.2 \times 10^{8}$ cells $/ \mathrm{cm}^{3}$ in 4 weeks, which is similar to cell density found in vivo, ${ }^{20}$ and decreased after this time. The density of cells on bonded PGA matrices increased throughout the 7 weeks of the experiment to reach a value of $2.1 \pm 0.3 \times 10^{8}$ cells $/ \mathrm{cm}^{3}$. The higher cell density on unbonded PGA matrices over that on bonded PGA matrices was caused by matrix contraction rather than by cell growth since the number of cells growing on unbonded PGA matrices was less than that on bonded PGA matrices.

The synthesis of elastin, a significant extracellular protein in SM tissue that largely determines the mechanical properties of SM tissue, in the engineered tissues also was examined. Verhoeff's staining indicated that the extracellular matrix in both engineered SM tissues contained elastin, as indicated by the dark, positive staining of the tissue sections (Fig. 13). Quantification of elastin revealed a large elastin deposition in SM tissues engineered on bonded matrices (Fig. 14). These tissues contained $310 \pm 51 \mu \mathrm{g}$ of elastin per tissue construct after 7 weeks in culture. This amounts to $30 \%$ of the dry mass of the SM tissue construct (excluding the polymer content), and this elastin content is similar to that of native SM tissue. ${ }^{21} \mathrm{SM}$ tissues engineered on unbonded PGA matrices contained only $188 \pm 10 \mu \mathrm{g}$ of elastin per tissue construct after 4 weeks in culture, and the elastin content did not increase after that time point.

\section{DISCUSSION}

Physically bonded PGA fiber-based matrices can be used as a synthetic ECM to guide the development of three-dimensional SM tissues with a predefined configuration in vitro. Physical bonding of adjacent PGA fibers greatly decreased contraction of matrices during tissue development, likely due to enhancement of mechanical properties and a decrease in degradation rate. The new tissues formed on physically bonded PGA matrices exhibited a high cell density and ECM deposition.

Various methods previously have been used to stabilize PGA fiber-based matrices. PGA fibers physically can be bonded with a secondary polymer simply by dipping the PGA matrices into a solution of PLLA

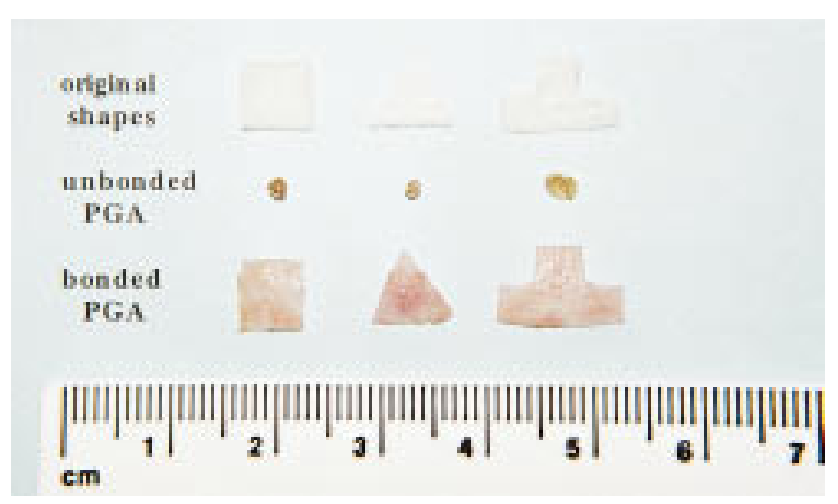

Figure 9. Photograph demonstrating final gross shapes of tissue constructs engineered on either unbonded PGA matrices or bonded PGA matrices (bonding PLLA mass $=136 \%$ of the initial PGA mass) fabricated into specific geometries. Tissues were allowed to develop for 8 weeks in vitro. 


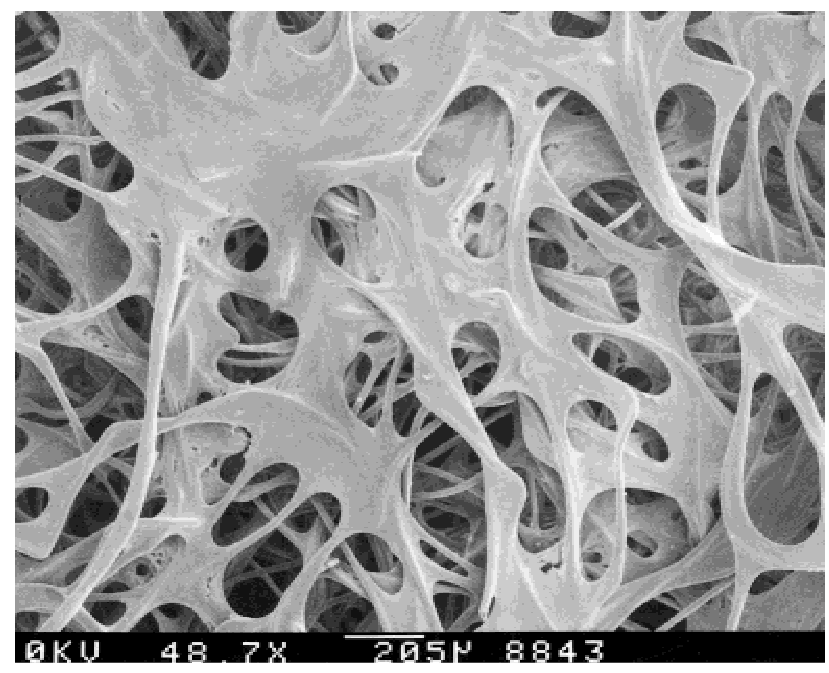

(a)

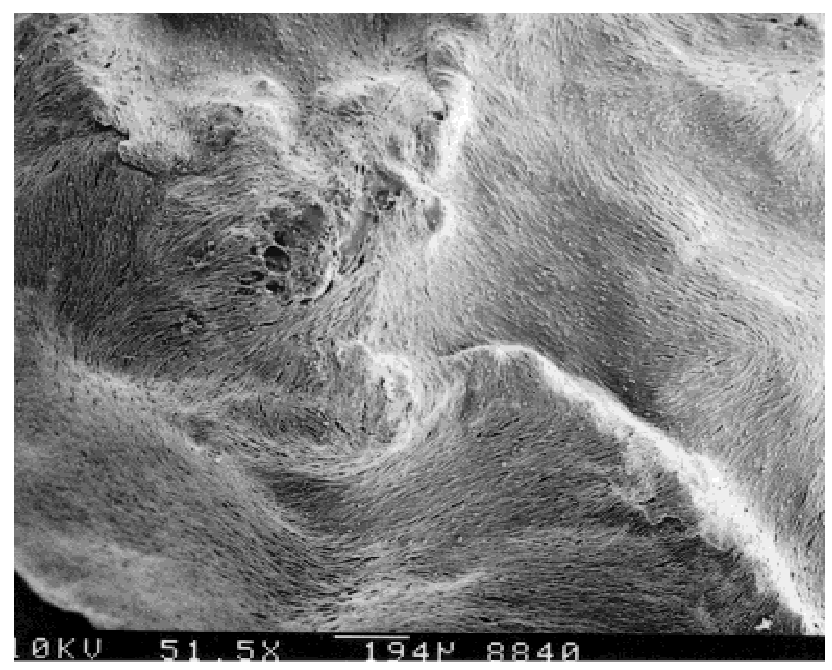

(c)

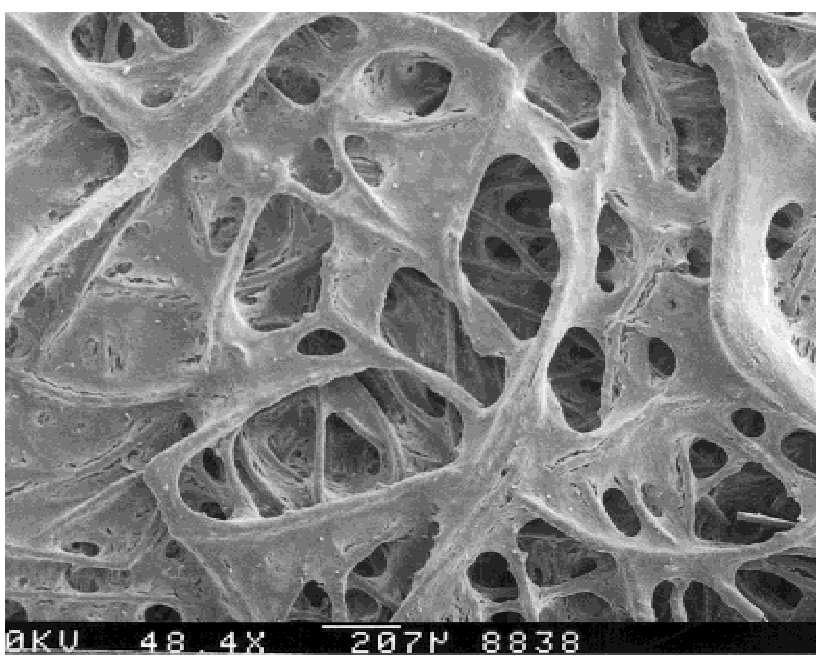

(b)

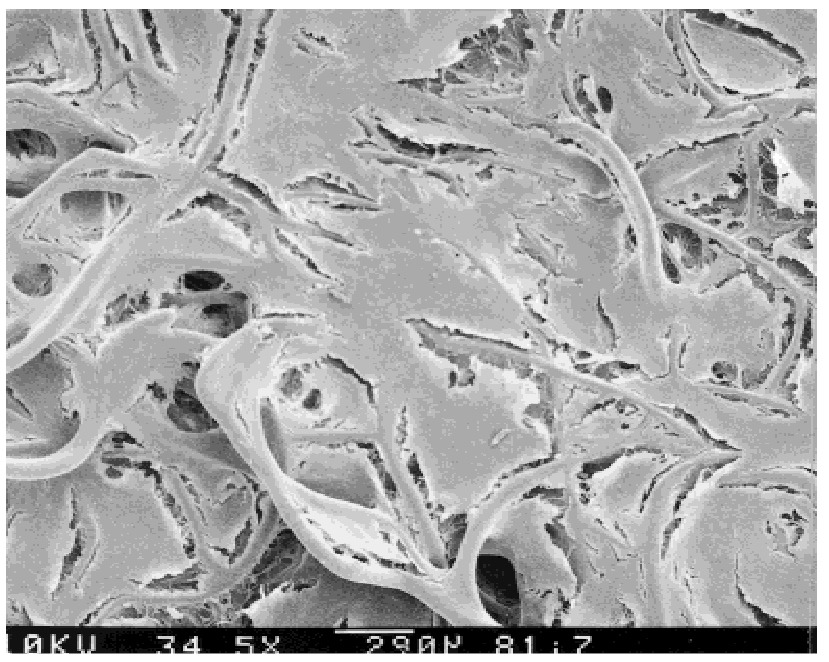

(d)

Figure 10. Scanning electron micrographs of the exterior of SMC-seeded unbonded PGA matrices (a,c) and bonded matrices $(b, d)$ after 1 week $(a, b)$ and 4 weeks $(c, d)$ in culture. The original magnifications and size bars are shown in the photomicrographs.

dissolved in chloroform and allowing the chloroform to evaporate. ${ }^{22}$ This process is simple, but physical bonding may not be uniform throughout the PGA matrices, and it may form at just some crosspoints of adjacent PGA fibers. In addition, since PLLA is concentrated at crosspoints of PGA fibers (similar to bonded and annealed PGA matrices), the degradation pattern may not be significantly different from that of unbonded PGA matrices. In another method, thermal treatment of PGA fiber-based matrices embedded in PLLA resulted in temporary melting and subsequent bonding of adjacent PGA fibers. ${ }^{23}$ Since the matrices prepared with this method have the same chemical composition as the original unbonded matrices, the degradation pattern is likely to be similar to that of unbonded PGA matrices. The mechanical properties of PGA matrices bonded with these two other methods have not been reported.
A cell delivery device must maintain a predefined geometry in the face of cellular and external forces during the process of tissue development to engineer a tissue with a desired three-dimensional structure. This potentially can be achieved by optimizing mechanical and degradative properties of the matrices. These properties of PGA fiber-based matrices were improved in this study by physical bonding of adjacent PGA fibers. The bonding approach used in this study allows one readily to tailor mechanical properties by controlling the extent of bonding. The tensile (not shown) and compressive resistance of bonded and bonded and annealed PGA matrices significantly increased compared with that of unbonded PGA matrices, depending on the extent of bonding. The degradative properties also were altered by PLLA bonding on PGA matrices. The degradation rate of bonded PGA matrices was very slow while unbonded PGA 


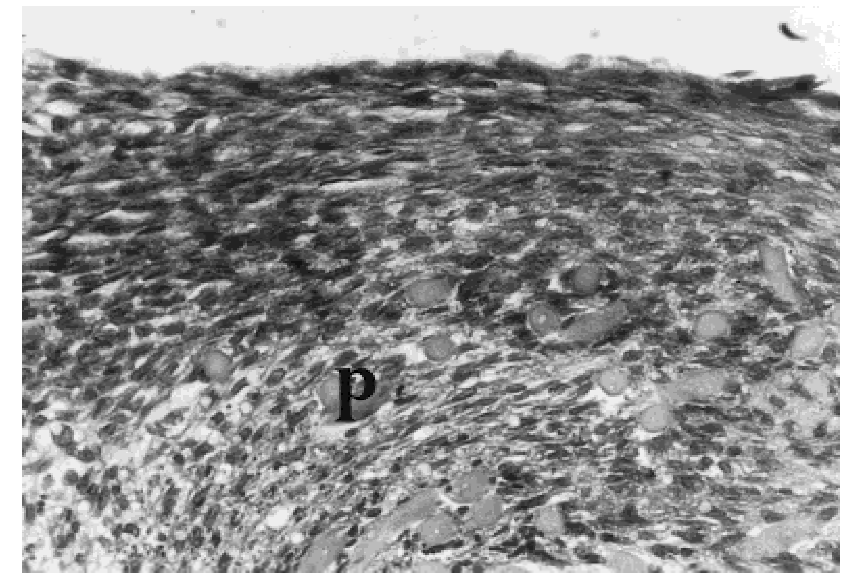

Figure 11. H\&E-stained cross section of SM tissue engineered on unbonded PGA matrix for 4 weeks in vitro. Polymer fibers $(\mathrm{P})$ are visible in the photomicrograph along with the new SM tissue. The original magnification of the photomicrograph was $\times 400$.

matrices largely were degraded within 7 weeks. PLLA typically is hydrolyzed very slowly, and the mass loss observed in bonded PGA matrices likely was due to hydrolysis of the PGA portion of the matrices. ${ }^{2}$ Past studies have demonstrated that the degradation of polyanhydride matrices can be delayed by coating with the more hydrophobic polylactide. ${ }^{24}$ The decrease in the degradation rate of bonded PGA matrices found in the present study likely was caused by a similar decrease in $\mathrm{H}_{2} \mathrm{O}$ access to PGA by the coating of the hydrophobic PLLA. The bonded and annealed matrices degraded faster than bonded matrices although the degradation rate is slower than that of unbonded matrices. Annealing resulted in loss of the PLLA coating as it condensed, and the degradation of the PGA was similar to the untreated control. The compressive modulus of unbonded PGA matrices dramatically decreased to $1.1 \mathrm{kPa}(12 \%$ of the initial compressive modulus) after 5 weeks of incubation in the solution, probably due to the fast degradation of these matrices. However, bonded matrices, which have good initial mechanical properties and a slower degradation rate, maintained a relatively high modulus of $25.2 \pm 9.7 \mathrm{kPa}$ ( $28 \%$ of initial compressive modulus) following degradation for 5 weeks. Bonded and annealed matrices exhibited similar initial mechanical properties as bonded matrices, but they both degraded and lost their mechanical stability more quickly. Exogenous ECMs provide mechanical support to guide tissue development in the initial stage. As a new tissue is formed, the exogenous ECMs degrade and mechanical integrity is supported by the tissue itself. Bonded and annealed matrices likely could not provide sufficient structural stability in spite of their high initial mechanical properties because of their rapid degradation. The findings of the present study suggest that both the mechanical and degradative properties are critical for maintaining the structural stability of an exogenous ECM during the process of tissue development.

Bonded PGA matrices allowed appropriate SM tissue development in vitro. Bonding PGA matrices with PLLA did not affect SMC attachment while the annealing of bonded PGA matrices exhibited a lower SMC seeding efficiency. The PLLA crystallinity increased after annealing, but it is not clear if there is any relationship of this change to cell seeding. Cells seeded on the bonded matrices proliferated and formed a tissue with a cell density of $2.1 \pm 0.3 \times 10^{8}$ cells $/ \mathrm{cm}^{3}$ by 7 weeks, at which time cell density was still increasing. The cell density in engineered SM tissue was higher when unbonded PGA matrices were used than bonded PGA matrices. However, this was not a result

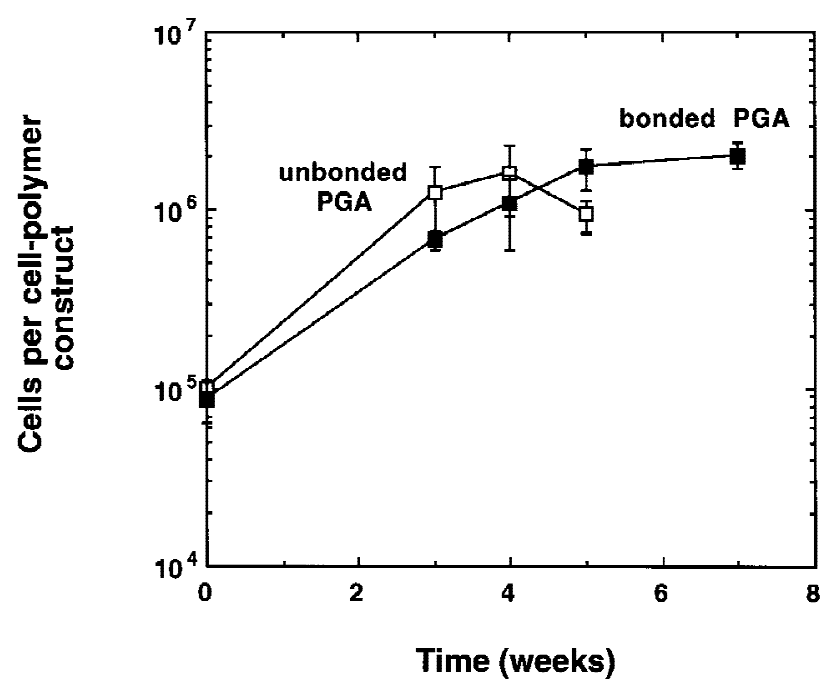

(a)

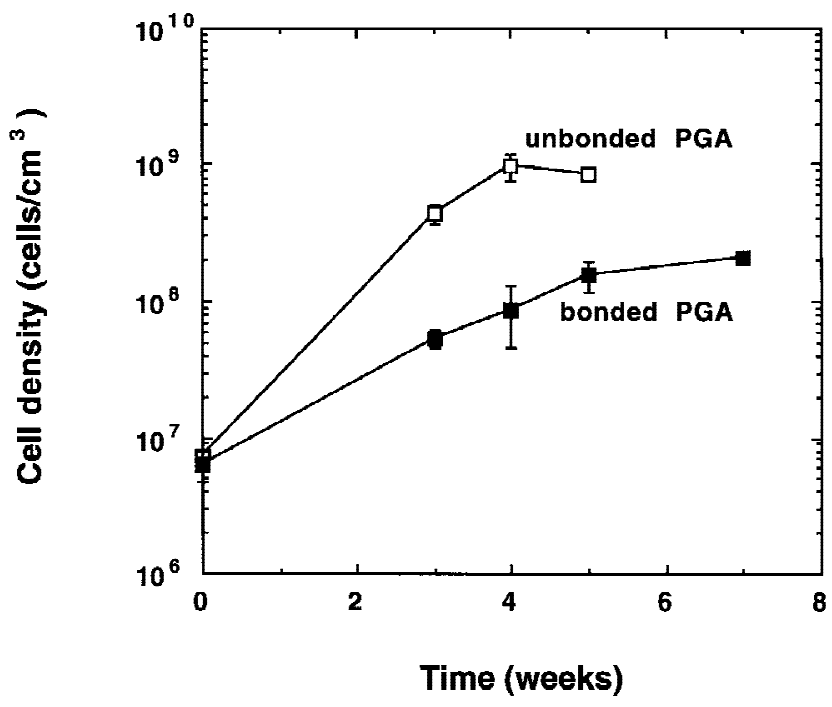

(b)

Figure 12. (a) Number of cells and (b) cell density of cellpolymer constructs over a 7-week culture period. Values represent the mean and standard deviation. 
of increased cell growth but instead resulted from the extreme contraction and loss of the desirable structure of these matrices. Previous studies indicate that these SMCs on PGA matrices produce little collagen, a major component of SM tissue. ${ }^{16} \mathrm{SM}$ tissues engineered from both types of matrices were found to contain elastin, which is a major extracellular protein in native SM tissue and largely determines the mechanical properties of SM tissue. What is important, tissues engineered with bonded matrices contained more elastin than those formed with unbonded matrices. This probably was caused by the higher cell number in these tissues. Thus bonded PGA matrices allow one to engineer new SM tissues with a high cellularity and ECM content and in specific complex forms (Fig. 9).

In conclusion, PGA fiber-based matrices can be modified to yield structures with specific shapes and appropriate mechanical properties to engineer a variety of tissues with desirable shapes and sizes. Both the initial mechanical properties and degradation rate of the matrices must be matched to the timing of tissue development to allow one to predefine an engineered tissue structure. Other types of bonding polymers and

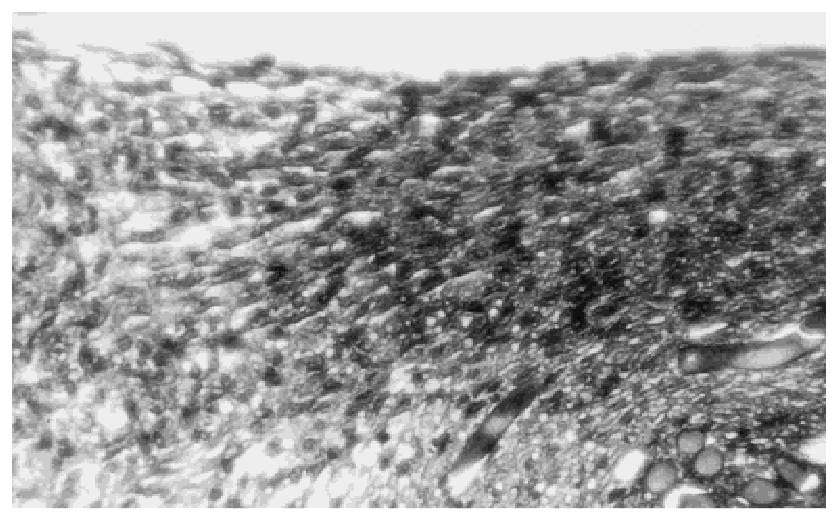

(a)

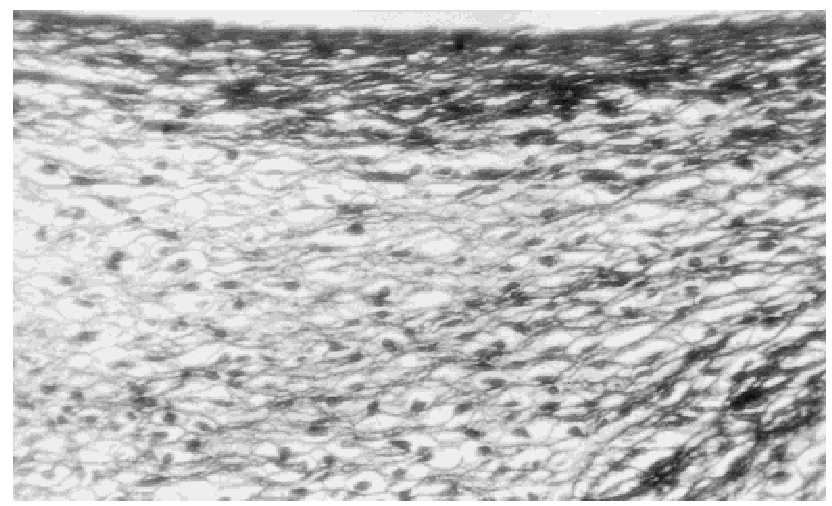

(b)

Figure 13. Verhoeff's stained cross sections of SM tissues engineered on unbonded PGA matrix for 4 weeks in vitro (a) and on bonded matrix for 7 weeks in vitro (b). These sections were not counterstained; thus the dark color represents positive staining for elastin. The original magnification of these photomicrographs was $\times 400$.

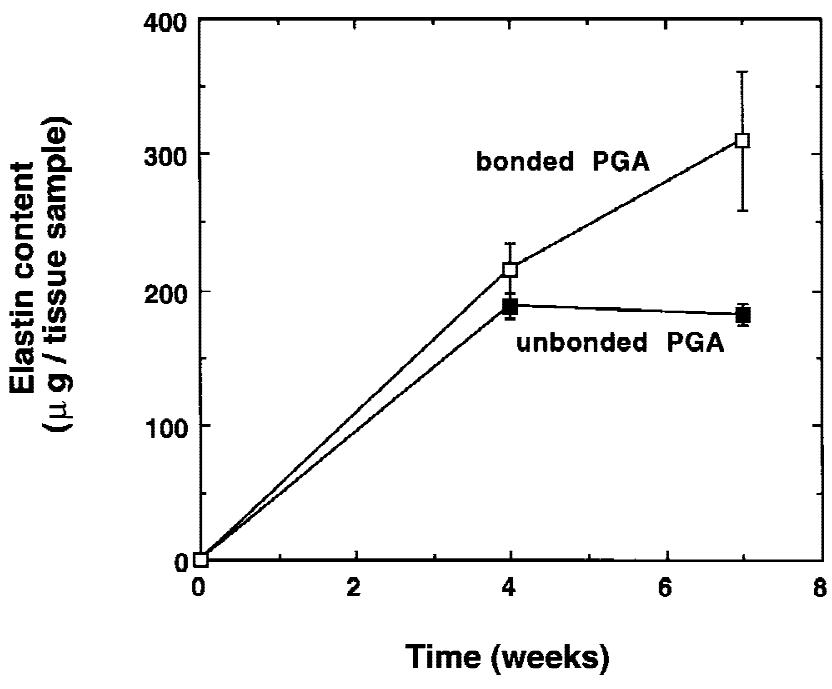

Figure 14. Elastin content of cell-polymer constructs over a 7-week culture period. The difference between elastin contents in constructs engineered with unbonded PGA and bonded PGA on week 7 was statistically significant $(p<$ $0.05)$. Values represent the mean and standard deviation.

fiber-based matrices also could be used to further vary the mechanical and degradative properties of the matrices.

The authors thank Helena Hennighausen and Andrea Brown for technical assistance.

\section{References}

1. R. Langer and J. P. Vacanti, "Tissue engineering," Science, 260, 920-926 (1993).

2. D. J. Mooney, C. L. Mazzoni, C. Breuer, K. McNamara, D. Hern, J. P. Vacanti, and R. Langer, "Stabilized polyglycolic acid fibre-based tubes for tissue engineering," Biomaterials, 17, 115-124 (1996).

3. D. J. Mooney, C. Breuer, K. McNamara, J. P. Vacanti, and R. Langer, "Fabricating tubular devices from polymers of lactic and glycolic acid for tissue engineering," Tissue Eng., 1, 107118 (1995).

4. L. E. Freed, J. C. Marquis, A. Nohia, J. Emmanual, A. G. Mikos, and R. Langer, "Neocartilage formation in vitro and in vivo using cells cultured on synthetic biodegradable polymers," $J$. Biomed. Mater. Res., 27, 11-23 (1993).

5. A. G. Mikos, G. Sarakinos, S. M. Leite, J. P. Vacanti, and R. Langer, "Laminated three-dimensional biodegradable forms for use in tissue engineering," Biomaterials, 14, 323-330 (1993).

6. D. J. Mooney, D. F. Baldwin, J. P. Vacanti, and R. Langer, "Novel approach to fabricate porous sponges of poly(D,Llactic-co-glycolic acid) without the use of organic solvents," Biomaterials, 17, 1417-1422 (1996).

7. D. J. Mooney, G. Organ, J. P. Vacanti, and R. Langer, “Design and fabrication of biodegradable polymer devices to engineer tubular tissue," Cell Transplant., 3, 203-210 (1994).

8. J. Goshima, V. M. Goldverg, and A. I. Caplan, "The origin of bone formed in composite grafts of porous calcium phosphate ceramic loaded with marrow cells," Clin. Orthop. Rel. Res., 157, 259-278 (1991).

9. T. Ziegler and R. M. Nerem, “Tissue engineering a blood ves- 
sel: Regulation of vascular biology by mechanical stresses," $J$. Cell. Biochem., 56, 204-209 (1994).

10. J. Hirai and T. Matsuda, "Self-organized, tubular hybrid vascular tissue composed of vascular cells and collagen for lowpressure-loaded venous system," Cell Transplant., 4, 597-608 (1995).

11. A. Atala, W. Kim, K. T. Paige, C. A. Vacanti, and A. Retik, "Endoscopic treatment of vesicoureteral reflux with a chondrocyte-alginate suspension," J. Urol., 152, 641-643 (1994).

12. L. Benedetti, R. Cortivo, T. Berti, A. Berti, and F. Pea, "Biocompatibility and biodegradation of different hyaluronan derivatives (Hyaff) implanted in rats," Biomaterials, 14, 1154-1160 (1993).

13. N. E. Larsen, C. T. Pollak, K. Reiner, E. Leshchiner, and E. A. Balazs, "Hylan gel biomaterial: Dermal and immunologic compatibility," J. Biomed. Mater. Res., 27, 1129-1134 (1993).

14. V. Dixit, "Development of a bioartificial liver using isolated hepatocytes," Artif. Organs, 18, 371-384 (1994).

15. W. C. Puelacher, D. Mooney, R. Langer, J. Upton, J. P. Vacanti, and C. A. Vacanti, "Design of nasoseptal cartilage replacements synthesized from biodegradable polymers and chondrocytes," Biomaterials, 15, 774-778 (1994).

16. B.-S. Kim, A. J. Putnam, T. J. Kulik, and D. J. Mooney, "Optimizing seeding and culture methods to engineer smooth muscle tissue on biodegradable polymer matrices," Biotechnol. Bioeng., 57, 46-54 (1998).

17. D. J. Mooney, C. Powell, J. Piana, and B. Rutherford, "Engineering dental pulp-like tissue in vitro," Biotechnol. Prog., 12, 865-868 (1996).
18. A. Rothman, T. J. Kulik, M. B. Taubman, B. C. Berk, C. W. J. Smith, and B. Nadal-Ginard, "Development and characterization of a cloned rat pulmonary arterial smooth muscle cell line that maintains differentiated properties through multiple subcultures," Circulation, 86, 1977-1986 (1992).

19. Y. J. Kim, R. L. Y. Sah, J.-Y. H. Doong, and A. J. Grodzinsky, "Fluorometric assay of DNA in cartilage explants using Hoechst 33258," Anal. Biochem., 174, 168-176 (1988).

20. L. B. Kleinert, J. B. Hoying, and S. K. Williams, "The neointima formed in endothelial cell-seeded ePTFE vascular grafts results from both cellular-hyperplasia and extracellular-hypertrophy," Cell Transplant., 5, 475-482 (1996).

21. N. Simionescu and M. Simionescu, "The cardiovascular system," in Cell and Tissue Biology, 6th ed., L. Weiss (ed.), Urban \& Schwarzenberg, Baltimore, 1998, pp. 353-400.

22. C. A. Vacanti, L. G. Cima, D. Ratkowski, J. Upton, and J. P. Vacanti, "Tissue-engineered growth of new cartilage in the shape of a human ear using synthetic polymers seeded with chondrocytes," in Tissue-Inducing Biomaterials, L. G. Cima and E. S. Ron (eds.), Materials Research Society, Pittsburgh, 1992, pp. 367-374.

23. A. G. Mikos, Y. Bao, L. G. Cima, D. E. Ingber, J. P. Vacanti, and R. Langer, "Preparation of poly(glycolic acid)-bonded fiber structures for cell attachment and transplantation," J. Biomed. Mater. Res., 27, 183-189 (1993).

24. A. Göpferich, "Erosion of composite polymer matrices," Biomaterials, 18, 397-403 (1997). 